\title{
A SCHEME FOR THE PREVENTION OF CROSS INFECTION IN CHILDREN'S WARDS
}

\author{
BY \\ N. M. JACOBY, M.D., M.R.C.P. \\ Registrar to Children's Department, Guy's Hospital; Physician, E.M.S.
}

Cross infection is a major problem in the management of childrens' wards. In infancy it frequently proves fatal, and in older children lengthens the period of hospitalization, or may even, as in rheumatic fever and nephritis, adversely affect the prognosis. The sources of cross infection are twofold: from patient to patient and ward staff to patient. The transmission of the infection may be by three routes, inhalation, ingestion and implantation. The scheme here described is designed to guard against these dangers as far as is possible.

The experiment was carried out over a period of one year in a new childrens' ward, at the County Hospital, Pembury. A plan of the ward, fig. 1, shows that it is divided into either single rooms or small wardlets, all except one facing south, and opening by wide doors on to a covered balcony. There is adequate provision of sterilizers, sluices, kitchen space and milk room. Unfortunately there is no running water in any of the rooms, and washbasins could only be provided in the corridors owing to wartime difficulties.

It will be noted that the eastern section of the ward, consisting of five small single rooms, sterilizing room, sluice and bathroom, is separated from the rest of the ward, except through swing doors at the eastern end of the main corridor. In the centre of the south side there are two further small single rooms (A and B) with their own sluice, forming another semi-isolated unit. In the wardlets the maximum number of beds is six, and the minimum distance between beds 4 feet.

The experiment done in this ward, was conducted as follows:-

1. Distribution of cases. In order to prevent cross infection from patient to patient, great care was taken over placing each child. On admission all cases were classified and distributed as follows:

Class 1. Infants up to eighteen months of age, who had no infection of any kind, e.g. feeding difficulty, pyloric stenosis, erythroblastosis foetalis, congenital deformities. These infants, who suffer most from cross infection, were given the highest priority in bed isolation. They were admitted to the single rooms at the eastern end of the ward, where no case of known or suspected infection was ever allowed.
Class 2. Infants up to eighteen months of age, who although suffering from an infection which excluded them from class 1 are themselves equally susceptible to cross infection, e.g. pemphigus, impetigo, eczema, congenital syphilis, ophthalmia neonatorum. These infants were admitted to the single rooms $\mathrm{A}$ and $\mathrm{B}$.

Class 3. Children over the age of eighteen months suffering from non-infectious disease, e.g. rheumatic fever, chorea, nephritis, diabetes, epilepsy. These children were admitted to the larger wardlets (four to six bedded) from which all other classes were rigidly excluded.

Class 4. Children of all ages suffering from infectious diseases, e.g. tonsillitis respiratory infection, alimentary infection, otitis media. These cases were admitted to the small wardlets, keeping one type of disease in each wardlet as far as possible.

Class 5. Children of all ages suffering from tuberculosis. These cases were admitted to the large wardlet at the western end of the ward. This room was originally designed as a solarium, and was well suited for the treatment of tuberculosis.

In practice, patients were frequently moved from one room to another in order to accommodate the various classes, which varied in size all the time. Thus, except for the small single rooms and the tuberculosis wardlet, rooms were not specifically earmarked for clean or infectious cases, but the two were not mixed in the same room. It is obvious, however, that with a scheme such as this there will be occasions when although there are empty beds in the ward, further cases cannot be admitted unless they are of the particular class for which there is a vacancy. This small loss of bed accommodation is probably more than compensated for by shortening the stay of cases in hospital, and not having to shut the ward because of cross infection.

2. Nursing. The quantity and quality of the nurses is of paramount importance. The war made it impossible to get sufficient nurses, though there was an average of ten on day duty and four at night. On account of ' off duty' sickness and lectures, there was rarely this number at any one time. The infants were nursed by the sister, staff nurse and senior probationers. only. The other cases were divided amongst the less senior nurses, who each 


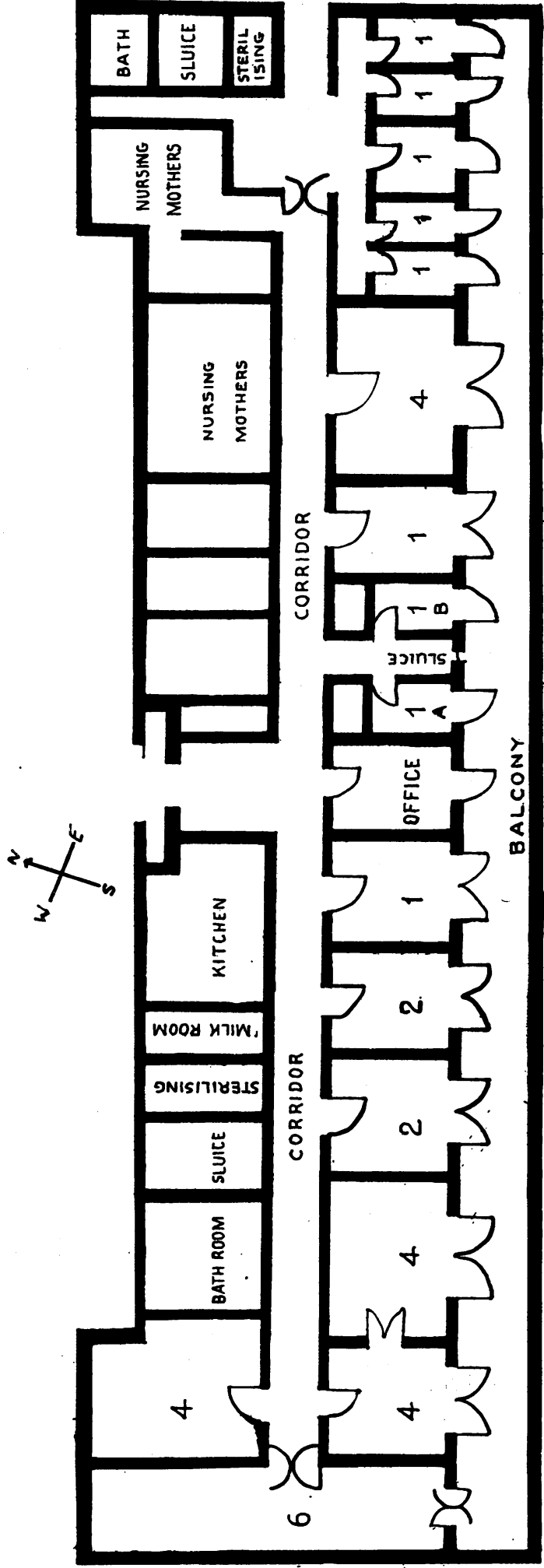

FIG. 1.-Scale plan of ward. Figures in each wardlet indicate the number of beds it contains. Door and window arrangements are shown for wardlets only. The unlabelled rooms are for administrative staff. had sole charge of a certain number, depending on her seniority. As far as possible no nurse was given charge of 'clean' and infected cases at the same time.

3. Masking. All doctors, nurses, students, cleaners, visitors and anyone else who wished to enter a ward was required to wear a gauze mask covering nose and mouth. The masks were worn once and then sterilized.

4. Barrier nursing. Infectious cases were nursed on full barrier precautions. In all other cases reasonable precautions were taken to prevent spread of infection by the ward staff. Children who were not continuously in bed were not allowed to leave their rooms.

5. Preparation of food. The infants' feeds were prepared by the sister or staff nurse using full aseptic technique. The bottles were stored in a refrigerator until required. No precautions, other than those in general use in the hospital, were taken over the food of the older children.

6. Visitors. Visitors were discouraged and reduced to a minimum. They were not allowed in the wardlets except in the cases of grave illness. No child under fourteen years of age was allowed to visit.

7. Specific infectious fevers. Owing to local conditions, only cases of diphtheria and scarlet fever could be admitted to the isolation hospital. Children developing any other specific infectious fever had to remain in the ward. The procedure adopted in such circumstances was to close the wardlet immediately concerned and give passive immunity (if a preparation existed) to the contacts. The rest of the ward remained in full operation.

\section{Results}

TABLE I

\section{CASES DEVELOPING CROSS INFECTION}

\begin{tabular}{c|c|c|c|c|c}
\hline $\begin{array}{c}\text { Class } \\
\text { of } \\
\text { case }\end{array}$ & $\begin{array}{c}\text { No. } \\
\text { of } \\
\text { cases }\end{array}$ & $\begin{array}{c}\text { No. } \\
\text { Cross } \\
\text { in- } \\
\text { fected }\end{array}$ & $\begin{array}{c}\text { Per } \\
\text { cent. }\end{array}$ & $\begin{array}{c}\text { Deaths } \\
\text { due tó } \\
\text { Cross } \\
\text { in- } \\
\text { fection }\end{array}$ & $\begin{array}{c}\text { Mortal- } \\
\text { ity rate, } \\
\text { per } \\
\text { cent. }\end{array}$ \\
\hline 1 & 47 & 2 & $4 \cdot 3$ & 1 & $2 \cdot 15$ \\
2 & 27 & 1 & $3 \cdot 7$ & 1 & $3 \cdot 7$ \\
3 & 85 & 6 & 7 & 0 & 0 \\
4 & 96 & 5 & $5 \cdot 2$ & 0 & 0 \\
5 & 13 & 2 & $15 \cdot 4$ & 0 & 0 \\
\hline Total. & 268 & 16 & 6 & 2 & 0.75 \\
\hline
\end{tabular}

Table I shows the incidence of cross infection in each class. The best results were obtained in classes 1 and 2 , and this is not surprising as they were given the best nursing and bed isolation. It is gratifying to find that the highest degree of protection is provided for the children who suffer most from cross infection, as is shown by the fact that of the three cases that did occur, two proved fatal. 
The highest incidence of cross infection was amongst the tuberculous children, and this is readily explained by the fact that they occupied the largest wardlet, and stayed in hospital for very long periods.

The total incidence at 6 per cent. appears to be of a low order compared with 18.9 per cent. (Wright, 1940), and 11 per cent. for diarrhoea alone (Evans, 1942).

\section{TABLE II}

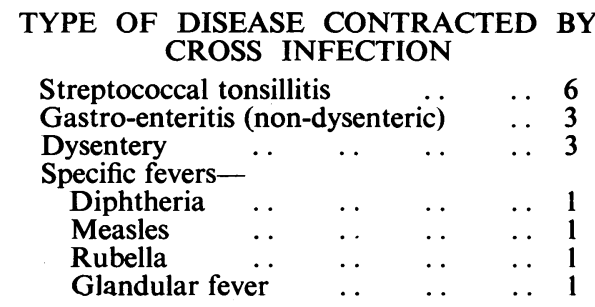

Table II shows the type of disease contracted by cross infection. The source of infection in most cases could not be traced, but one case of dysentery was due to a ward cleaner (subsequently found to be a carrier) feeding a child, contrary to regulations. The case of diphtheria was contracted from a nurse, and the glandular fever from a house officer. The cases of measles and rubella both developed within their respective incubation periods after admission. It is almost certain that they were not true cases of cross infection, but were developing the disease on admission.

\section{TABLE III}

\section{MONTHLY INCIDENCE OF CROSS INFECTION COMPARED WITH MONTHLY PATIENT DAY MAINTENANCE}

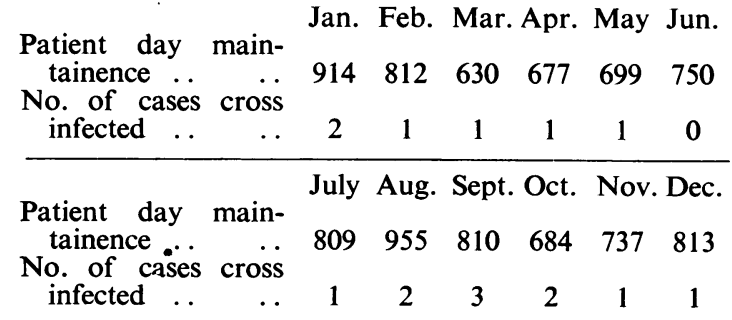

Table III shows there was no marked seasonal incidence, but that a small number of cases occurred each month. There is also no definite relationship between 'patient day maintenance' and the number of children infected. It would thus appear that the scheme was as effective when the ward was fully or partially occupied.

\section{Conclusions}

The most important factor in preventing cross infection in a childrens' ward is bed isolation. Infants should always have separate rooms, but it is equally important that blocks of these rooms should be specifically allocated for 'clean' and infected infants. If possible, the blocks of rooms for each type should not be adjacent. For older children it is probably undesirable to have them in separate rooms. Though it would prevent cross infection, the psychological effects of solitary isolation are bad. The solution would appear to be in having a large number of small wardlets, mainly two bedded, the largest should not contain more than four beds. Into each wardlet there should be allowed only children suffering from the same class of disease.

On admission every case requires careful classification, and in this respect it would probably be useful to have a small number of single 'admission rooms' where doubtful cases could be temporarily placed. There is no need for all cases to go through these rooms, and if they did, the bed wastage would be greatly increased.

Second only to bed isolation in importance is the nursing staff. This should be large and competent. There should be a ratio of one nurse to two patients on day duty, and one to five at night.

Efficient face masking is essential. The present type of mask is not ideal, and probably a tight fitting rubber and gauze one could be devised, thus abolishing droplet infection from staff to patient.

If in the future childrens' wards are to be made safer than has generally been the case in the past, close attention will have to be paid to their architecture, and the staffing with nurses must be on a generous scale. Moreover, the number of beds for children will have to be increased. These facts will add to the cost of building and maintenance, but the saving of life will justify it.

Thanks are due to Sister M. Wilcock and many Guy's nurses, without whose co-operation this experiment could not have been carried out; also to the Medical Superintendant, Dr. E. D. Grasby for allowing the ward to be used.

\section{REFERENCES}

Evans, P. (1942). Arch. Dis. Childh., 17, 130.

Wright, J. (1940). J. Hyg., 40, 647. 